\title{
Fracture Toughness of Multilayer Pipes
}

\author{
E. Nezbedová, ${ }^{1, a}$ L. Fiedler, ${ }^{2, b}$ Z. Majer, ${ }^{2,3, c}$ B. Vlach, ${ }^{2, d}$ and Z. Knésl ${ }^{3, \mathrm{e}}$ \\ ${ }^{1}$ Faculty of Chemistry, Institute of Materials Science, Brno University of Technology, Brno, Czech \\ Republic \\ ${ }^{2}$ Faculty of Mechanical Engineering, Brno Technical University, Brno, Czech Republic \\ ${ }^{3}$ Institute of Physics of Materials, Academy of Science of the Czech Republic, Brno, Czech Republic \\ ${ }^{\mathrm{a}}$ nezbedova@fch.vutbr.cz, ${ }^{\mathrm{b}}$ fidlub@post.cz, ${ }^{\mathrm{c}}$ majer@ipm.cz, ${ }^{\mathrm{d}}$ vlach@fme.vutbr.cz, \\ ${ }^{\mathrm{e}}$ knesl@ipm.cz
}

Multilayer pipes composed of various materials improve partially the properties of a pipe system and are frequently used in service. To estimate the lifetime of these pipes the basic fracture parameters have to be measured. In the contribution a new approach to this estimation is presented. Special type of a $C$-shaped inhomogeneous fracture mechanics specimen machined directly from a pipe has been proposed, numerically analyzed and tested. The corresponding $K$ values are calculated by FEM and fracture toughness values of HDPE pipes material are obtained.

Keywords: polyethylene pipes, fracture toughness, $K$-calibration.

Introduction. Polyethylene (HDPE) and polypropylene (PP) materials can be considered modern and ecologic; they substitute for conventional pipe materials (steel, cast-iron). This progress is followed by relevant legislation (international standards, profession directives, national codes, etc.). According to these standards the lifetime of the newest bimodal type of HDPE [1] is expected to be up to 100 years. This long lifetime is guaranteed only if tubes are strained with just inner overpressure. Unfortunately, there are other factors in service, which can reduce this lifetime [2, 3]. These extraordinary circumstances can evoke creation of the stress raisers that can lead to forming of a crack and then to brittle failure of the whole pipe system. Using the fracture mechanics approaches [4-6] there have been developed methods and procedures which are able to evaluate the resistance of both native material and pipes from the view of a slow [7] and rapid crack growth [8].

The development of new materials has supported novel technologies, which could not be used so far in laying of new tubes and sanitation [9]. The so-called multilayer pipes have received a wider acceptance recently in the field of pipes systems. The purpose of the development was to improve partially the properties profile of pipes from nonchained polyethylene by combining with other materials. This method has essentially resulted in two types of pipes: (i) pipes with dimensional addition of a protective surface and (ii) pipes with a dimensionally integrated protective surface.

In our contribution we have focused on the second type of multilayer pipes and its lifetime expectation. Specifically, the fracture toughness was chosen as a relevant parameter for evaluation of a pipe material resistance to a so-called slow crack growth (SCG). This type of fracture occurs under long-term service conditions and limits the lifetime. To estimate fracture toughness of the pipe material a special inhomogeneous C-shaped specimen machined directly from the pipe (Fig. 1a) was proposed and numerically analyzed. Based on the numerical results the fracture mechanics parameters $K_{Q d}$ were estimated for two different temperatures.

Experimental. The three-layer commercial plastic pipe Wavin TS ( $\varnothing 110$ SDR11) with its outer and inner layers made of an extremely durable PE material (XSC 50) and its interlayer PE 100 was chosen as experimental material. The thickness of both inner and outer layers was $2.5 \mathrm{~mm}$ and that of the interlayer was $5 \mathrm{~mm}$ (Fig. 1b). 


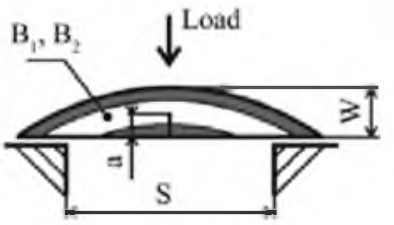

a

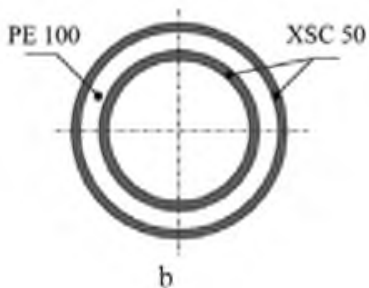

Fig. 1. C-shaped specimen and the experimental setup used for the fracture toughness measurements (a); schematic of the three-layer pipe (b)

The material mechanical characteristics (tensile modulus $E$ and yield stress $\sigma_{y}$ ) of individual layers were determined from standard tensile tests carried out according to standard CSN EN ISO 527-1. Tensile test specimens were directly cut from the pipe in the longitudinal direction of the pipe. Tests were carried out on the universal testing machine Zwick Z020. The load was measured using $2.5 \mathrm{kN}$ dynamometer and deformation was determined using an extensometer with accuracy class 0.5 . The testing conditions were as follows: initial gauge length $20 \mathrm{~mm}$, temperature $23^{\circ} \mathrm{C}$ and $-60^{\circ} \mathrm{C}$, and crosshead speed $1 \mathrm{~mm} / \mathrm{min}$. The obtained values of tensile modulus $E$ and yield stress $\sigma_{y}$ are summarized in Table 1.

$\mathrm{T}$ a b 1 e 1

The Mechanical Characteristics of the Pipe Layers

\begin{tabular}{|c|c|c|c|c|}
\hline \multirow{2}{*}{$\begin{array}{c}\text { Temperature } \\
{ }^{\circ} \mathrm{C}\end{array}$} & \multicolumn{2}{|c|}{$E, \mathrm{MPa}$} & \multicolumn{2}{c|}{$\sigma_{y}, \mathrm{MPa}$} \\
\cline { 2 - 5 } & Inner/outer layer & Intermediate layer & Inner/outer layer & Intermediate layer \\
\cline { 2 - 5 } & $x / s$ & $x / s$ & $x / s$ & $x / s$ \\
\hline 23 & $827 / 34$ & $1213 / 28$ & $16 / 1$ & $20 / 0$ \\
\hline-60 & $2740 / 99$ & $3399 / 91$ & $45 / 0$ & $48 / 0$ \\
\hline
\end{tabular}

Note. Here and in Table 2: $x$ is the mean value and $s$ is a corresponding standard deviation.

Fracture mechanics characteristics were determined using the two types of instrumented Charpy impact testers. The first one was a high-energy impact tester PSW $300 \mathrm{E} / \mathrm{MFL}$ with impact energy $150 \mathrm{~J}$. The second was a low-energy impact tester Fraktoskop K4J with impact energy $4 \mathrm{~J}$ (Fig. 1a). The notches were made by pressing a fresh razor blade into the specimens.

The test conditions on the both types of impact testers were as follows: test temperature $23^{\circ} \mathrm{C}$ and $-60^{\circ} \mathrm{C}$, impact rate $1 \mathrm{~m} / \mathrm{s}$, and span distance $40 \mathrm{~mm}$.

The specimen $10 \mathrm{~mm}$ thick was tested on the high-energy impact tester, while the specimen of $4 \mathrm{~mm}$ thickness was tested on the low-energy impact tester. Notches of three different depths $(3.8,4.6$, and $5.6 \mathrm{~mm})$ were made on 4 -mm-thick specimens. In the case of $10-\mathrm{mm}$-thick specimens the notches were of the same depth $-4.6 \mathrm{~mm}$. In all cases the crack tips were located in the interlayer PE 100 material. The resulting values of dynamic fracture toughness $K_{Q d}$ were calculated according to the equation

$$
K_{\varrho d}=\frac{F_{\max } S}{B W^{3 / 2}} f(a / W) .
$$

Here $F_{\max }$ is the maximum load, $S$ is the span distance, $B$ and $W$ are the thickness and width, respectively, $a$ is the notch depth, and $f(a / W)$ is a geometric factor. The 
geometric factor is known only for a homogeneous standard three-point bend specimen [9, 10]. The function $f(a / W)$ corresponding to the used C-shaped inhomogeneous three layers specimen has to be calculated numerically.

Numerical Model. The numerical model corresponds to the experimental setup. The material data correspond to those given in Table 1. The numerical analyses were carried out under plane strain conditions by using a finite element method as implemented in the standard ANSYS 10.0 system. To estimate the corresponding values of stress intensity factor $K_{\mathrm{I}}$ the standard K-CALC procedure implemented in ANSYS has been applied. As a result, the values of $K_{\mathrm{I}}$ were obtained and the corresponding function $f(a / W)$ was estimated according to Eq. (1), see Fig. 2. The geometric factor corresponding to the standard three-point bend specimen is added for comparison. Note that the $f(a / W)$ values are practically independent of Poisson's ratio. Using Eq. (1) and the results presented in Fig. 2, the values of the dynamic fracture toughness were estimated (Table 2). Note that according to the ASTM standard the only valid value of $K_{\mathrm{Ic}}$ is obtained for temperature $-60^{\circ} \mathrm{C}$ and for the specimen thickness $B_{2}=10 \mathrm{~mm}$.

The values of dynamic fracture toughness for two different specimen thicknesses and for temperatures $23^{\circ} \mathrm{C}$ and $-60^{\circ} \mathrm{C}$, determined using two types of instrumented Charpy impact testers, are given in Table 2 .

$\mathrm{T}$ a b 1 e 2

Resulting Values of Dynamic Fracture Toughness for Two Different Specimen Thicknesses

\begin{tabular}{|c|c|c|c|c|}
\hline \multirow{2}{*}{\begin{tabular}{|c|} 
Thickness, mm \\
\hline$a, \mathrm{~mm}$
\end{tabular}} & 3.8 & 4.6 & 5.6 & $B_{2}=10$ \\
\hline $\begin{array}{c}\text { Temperature, } \\
{ }^{\circ} \mathrm{C}\end{array}$ & \multicolumn{4}{|c|}{$K_{Q d}, \mathrm{MPa} \cdot \mathrm{m}^{1 / 2}$} \\
\cline { 2 - 5 } & $x / s$ & $x / s$ & $x / s$ & $x / s$ \\
\hline 23 & $3.0 / 0.4$ & $2.0 / 0.3$ & $1.2 / 0.1$ & $2.4 / 0.2$ \\
\hline-60 & $2.4 / 0.2$ & $1.8 / 0.3$ & $1.1 / 0.6$ & $3.5 / 0.1$ \\
\hline
\end{tabular}

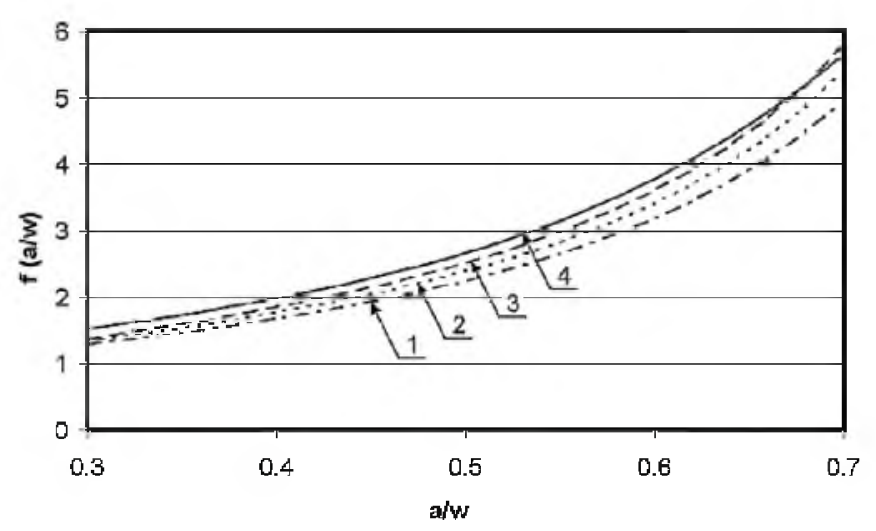

Fig. 2. Correction function $f(a / W)$ for a C-type specimen (middle layer): (I) homogeneous specimen; (2) temperature $T=-60^{\circ} \mathrm{C}$; (3) temperature $T=23^{\circ} \mathrm{C}$; (4) standard three-point bend specimen $[9,10]$.

Conclusions. We have studied the lifetime expectation of the three-layer commercial plastic pipe with dimensionally integrated protective surfaces was investigated. The fracture toughness is chosen as a relevant parameter for evaluation of the pipe material 
resistance to a slow crack growth. To evaluate fracture toughness values of the interlayer PE 100 pipe material the following steps have been made:

- the material parameters (tensile modulus $E$ and yield stress $\sigma_{y}$ ) for both inner and outer layers of the three layers pipe were determined for temperatures $23^{\circ} \mathrm{C}$ and $-60^{\circ} \mathrm{C}$;

- a new inhomogeneous C-shaped fracture mechanics specimen machined directly from the pipe has been used and the corresponding values of the stress intensity factor $K$ represented by the geometric factor $f(a / W)$ have been calculated by FEM;

- the values of dynamic fracture toughness for two different specimen thicknesses and for temperatures $23^{\circ} \mathrm{C}$ and $-60^{\circ} \mathrm{C}$ were determined using two types of instrumented Charpy impact testers

Acknowledgments. The authors gratefully acknowledge the support provided by the Grant Agency of the Czech Republic (No. 101/05/0227) for this work.

1. E. Nezbedovâ, A. Zahradnícková, and Z. Salajka, "Brittle failure versus structure of HDPE pipe grades," J. Macromol. Sci. - Physics, B40 (384), 507-515 (2001)

2. J. Hessel, "Mindesbendsdauer von erdverlegten Rohen aus Polyethylen ohne Sandeinbettung," Sonderdruck aus 3R International; 40 Jahrgang, Heft 4 (2001), SS. 178-184.

3. A. L. Ward, X. Lu, Y. Huang, and N. Brown, Polymer Testing, 11, 309 (1992).

4. M. Fleipner, "Langsames Risswachstum und Zeitstandfestingkeit von Rohren aus Polyethylene," Kunststoffe, 77, No. 1, 45-50 (1987).

5. S. J. Ritchie, P. Davis, and P. S. Leevers, "Brittle-tough transition of rapid crack propagation in polyethylene," Polymer, 39, 6657-6663 (1998).

6. ISO/CD 16770: Plastics. Determination of Environmental Stress Cracking (ESC) of Polyethylene (PE), Full Notch Creep Test (FNCT) and ISO/CD 16 241: Notch Tensile Test to Measure the Resistance to Slow Crack Growth of Polyethylene Materials for Pipe and Fitting Products (PENT).

7. ISO 13477:1997 Thermoplastics Pipes for the Conveyance of Fluids. Determination of Resistance to Rapid Crack Propagation (RCP). Small-Scale Steady-State Test (S4 Test).

8. Y. Savidus, "Progresivní postupy používané pĩi výstavbě potrubních vedení z plastu," 10 ročník mezinárodní konference Plasty v Rozvodech Plynu [in Czech], Sborník referátů, Praha (2003), str. 233.

9. ISO 13586: Determination of Fracture Toughness ( $G_{c}$ and $K_{c}$ ). Linear Elastic Fracture Mechanics (LEFM) Approach

10. W. Grellmann, S. Seidler, und W. Hesse, MPK-Prozedur: Prifung von Kunststoffen Instrumentierter Kerbschlagbiegeversuch, Merseburg (2005). 